\title{
Hydration Properties of Ground Granulated Blast-Furnace Slag (GGBS) Under Different Hydration Environments
}

\author{
Shuhua LIU*, Weiwei HAN, Qiaoling LI
}

\author{
State Key Laboratory of Water Resources and Hydropower Engineering Science, Wuhan University, Wuhan, 430072, \\ China \\ crossref http://dx.doi.org/10.5755/j01.ms.23.1.14934
}

Received 31 May 2016; accepted 22 June 2016

\begin{abstract}
The hydration properties of various cementitious materials containing Ground Granulated Blast-furnace Slag (GGBS), two alkali-activated slag cements (AAS-1 and AAS-2), in which sodium silicate and sodium hydroxide act as alkaline activators respectively, supersulfated cement (SSC) and slag Portland cement(PSC), are compared with ordinary Portland cement (OPC) to investigate the effect of activating environment on the hydration properties in this study by determining the compressive strength of the pastes, the hydration heat of binders within 96 hours, and the hydration products at age of 28 and 90 days. The results show that $\mathrm{C}-\mathrm{S}-\mathrm{H}$ gels are the main hydrated products for all cementitious systems containing GGBS. $\mathrm{Ca}(\mathrm{OH})_{2}$ is the hydration products of OPC and PSC paste. However, ettringite and gypsum crystals instead of $\mathrm{Ca}(\mathrm{OH})_{2}$ are detected in SSC paste. Additionally, tobermorite, a crystalline C-S-H, and calcite are hydrated products in AAS-1. Tobermorite, cowlesite and calcite are hydrated products of AAS-2 as well. Based on strength results, AAS-1 paste exhibits the highest compressive strength followed by OPC, PSC, SSC in order at all testing ages and AAS-2 give the lowest compressive strength except for the early age at 3 days, which is higher than SSC but still lower than PSC. From hydration heat analysis, alkalinity in the reaction solution is a vital factor influencing the initial hydration rate and the initial hydration rate from higher to lower is AAS-2, AAS-1, OPC, PSC and SSC. Although AAS possesses a faster reaction rate in the initial hours, cumulative hydration heat of AAS is comparably lower than that of OPC, but higher than those of PSC and SSC in turn, which indicates that the hydration heat of clinkers is much higher than that of slag.

Keywords: GGBS, slag Portland cement, supersulfated cement, alkali-activated slag cement, hydration properties.
\end{abstract}

\section{INTRODUCTION}

Portland cement is the most widely used cementitious materials in modern concrete in the world for its good binding property and high strength [1]. Statistical dates show that just in the year of 2012, the global cement production reached up to 2.4 billion tons, of which nearly $50 \%$ was contributed by China [2-4]. On one hand, the massive production is not only energy-intensive but also exerts negative effects on the environment because of the greenhouse gas emission during the calcining process. On the other hand, it is worth to being noted is the high hydration heat, which may cause the thermal cracking due to the accumulation of internal hydration heat in mass concrete. In order to overcome the drawbacks, Granulated Blast Furnace Slag (GGBS) is widely used as alternative to partially replace cement, or as a cementitious material per se after chemical activation in modern concrete, which has been found to have a relatively constant chemical composition, better workability, and higher ultimate strength compared to fly ash, and pozzolan besides the ecological, economical, and diversified product quality features shared by all of these supplementary cementitious materials [5-6].

GGBS is the finely ground powder of coarse blast furnace slag and considered as a latent hydraulic cementitious material, whose potential hydraulic activity is

\footnotetext{
* Corresponding author. Tel.: +86-27-68772233; fax: +86-27-68772310

E-mail address: shliu@whu.edu.cn (S. Liu)
}

closely related with two factors: (1) the vitreous phase fraction that account for more than $90 \%$ of GGBS and obtained during the process of coarse blast furnace slag production when the molten slag is rapidly cooled by quenching in the manufacture of pig iron from iron ore. The rest $10 \%$ or less of GGBS are crystalline phase. Only the vitreous phase, however, is the active component of GGBS, i.e., the more the vitreous fraction is, the greater the potential activity will be. Besides, it is welldocumented that the more the calcium rich phase and the less the silica rich phase in the structural composition of vitreous phase is, the greater the potential activity also be; (2) chemical composition dependent on the raw materials employed and potentially contains $27 \%-40 \% \quad \mathrm{SiO}_{2}$, $30 \%-50 \% \mathrm{CaO}, 5 \%-15 \% \mathrm{Al}_{2} \mathrm{O}_{3}$ and $1 \%-10 \% \mathrm{MgO}$ of which the last three terms are active component [7].

In order to activate of the latent hydraulic properties of GGBS at room temperature, Portland cement, gypsum and some alkalis have been used as activators in this study.

In general, PSC is comprised of $20 \%-70 \%$ slag as well as the resting are cement clinker acting as an activator and proper amount of gypsum according to Chinese National Standard GB 175-2007. The hydration of GGBS, in the presence of Portland cement, depends greatly upon the breakdown and dissolution of glassy slag structures by hydroxide anions generated by the cement clinkers hydration [8]. Compared with OPC, the hydration rate of PSC is slightly slow at room temperature, resulting in low early strength but high strength development at later age [9]. This is primary attributed to the small mass fraction of 
clinkers thereby the content of $\mathrm{C}_{3} \mathrm{~A}$ and $\mathrm{C}_{3} \mathrm{~S}$ are reduced, which feature by faster hydration rate and higher hydration heat. Compared with OPC, the hydration products of PSC are primarily $\mathrm{C}-\mathrm{S}-\mathrm{H}$ gel with low $\mathrm{Ca} / \mathrm{Si}$ ratio accompanying by a small amount of ettringite but few of $\mathrm{Ca}(\mathrm{OH})_{2}$ are formed because $\mathrm{Ca}(\mathrm{OH})_{2}$ generated by clinker in PSC not only serves as an alkaline activator but also reacts with active $\mathrm{SiO}_{2}$ and $\mathrm{Al}_{2} \mathrm{O}_{3}$.

In AAS, GGBS serves as a cementitious material per se after alkali activation most commonly in the form alkali hydroxide (AAS-1) and alkali silicate (AAS-2), which are chemical species capable of accelerating the break-up and hydration of slag. Compared with OPC and PSC, clinkerless AAS binders under proper condition usually present earliest and highest mechanical strength, largest resistance to chemical attack $[10-12]$. In spite of the acceleration of slag hydration by alkaline activator, it has been reported that AAS with proper mixture ratio and activator modulus has lower heat evolution rate and total heat evolution than OPC, but higher than PSC in some cases $[10,19]$. With regard to hydration products of AASs, Consensus usually achieved that C-(A)-S-H, a gel-like phase with a low $\mathrm{Ca} / \mathrm{Si}$ ratio and a high $\mathrm{Al}$ incorporation, is the main hydration product of AAS. Besides, no $\mathrm{Ca}(\mathrm{OH})_{2}$ is found in the hydration in the hydration products of AAS. The formation of other hydrated compounds, however, affected significantly by the chemical composition and structure of slags, type and concentration of activators, as well as the curing condition [13-15].

For the case of SSC, this kind of cement consists of almost $75 \%-85 \%$ GGBS, $10 \%-20 \%$ gypsum as sulfate activator and less than $5 \%$ clinker or lime as alkali activator [16]. GGBS can limit chemical reaction to some degree and the delayed coagulation of gypsum. SSC show lowest heat release and early strength when compared to OPC and PSC from previous study [17]. However, the strength growth at later age is considerable because of the stimulation of slag [18]. The main hydration products are ettringite, gypsum and C-S-H gel $[19,20]$. Gruskovnjak et al. observed that the reactivity of slag in SSC lied in the intrinsic dissolution rate of the slag, which mainly depended on the chemical composition rather than the glassy phase [16]. Different intrinsic dissolution rates of the slag lead to the diversity in early strength, which influences the mechanisms at the solid-water interface and thus the growth mechanisms of the hydrates.

The hydration properties vary widely due to the difference of activating environment. While the investigations comparing the effect of activating environment on hydration properties of several extensively studied cementitious systems stated above are uncommon in existing literatures [21-23]. The purpose of this paper aims at comparing the hydration properties of different cementitious materials containing GGBS to figure out the effect of activating environment on hydration properties including hydration heat, strength development, hydration products, and microstructure.

\section{EXPERIMENTAL}

The raw materials used in this study including OPC, GGBS, sodium hydroxide and sodium silicate as alkaline activators, as well as phosphogypsum and clinkers prepared for SSC. The specific surface area of GGBS is measured as $390 \mathrm{~m}^{2} / \mathrm{kg}$ and the chemical composition of these raw materials determined by X-ray fluorescence (XRF) is listed in Table 1. From this table, it can be seen that the contents of $\mathrm{SiO}_{2}$ and $\mathrm{Al}_{2} \mathrm{O}_{3}$ in cementitious system increase while the $\mathrm{CaO}$ content shows a downward trend in the order of OPC, PSC, SSC and GGBS due to the increased slag dosage and the reduction of clinker dosage. The water to binder ratio for all paste is 0.4 . What added to OPC, PSC and SSC is just tap-water, and alkaline solutions are prepared and added to GGBS to make alkali-activated slag cement. With respect to alkaline activators, sodium silicate (modulus $\mathrm{M}=\mathrm{n}\left(\mathrm{SiO}_{2}\right) / \mathrm{n}\left(\mathrm{Na}_{2} \mathrm{O}\right)=3.3$ ) solution and sodium hydroxide pellets of industrial grade are purchased from Dongyue Sodium silica Corporation (Shangdong, China), of which the modulus of sodium silicate is modified to 1.25 by adding $\mathrm{NaOH}$ previously dissolved in water, as shown in Table 2 . The mixed activating solutions were cooled down to room temperature prior to further use.

Table 2. Composition in activating solutions with respect to $1 \mathrm{~kg}$ GGBS

\begin{tabular}{|c|c|c|c|}
\hline Samples & $\mathrm{SiO}_{2}, \mathrm{~mol}$ & $\begin{array}{c}\mathrm{Na}_{2} \mathrm{O}, \mathrm{mol} \\
(\text { mass, \%)* }\end{array}$ & $\mathrm{H}_{2} \mathrm{O}, \mathrm{g}$ \\
\hline Sodium silicate & 1 & $0.8(5.0 \%)$ & 400 \\
\hline Sodium hydroxide solution & 0 & $0.8(5.0 \%)$ & 400 \\
\hline * Mass percentage with respect to GGBS content \\
\hline
\end{tabular}

The rates of heat evolution and the hydration heat release of all pastes with same water to cement ratio 0.4 were determined by a thermometric isothermal conduction calorimeter (Toni DCA7338), and the dosage is 10g with accuracy $0.001 \mathrm{~g}$.

According to the mix proportion of the pastes shown in Table 3, $40 \times 40 \times 40 \mathrm{~mm}^{3}$ cubic specimens were prepared by the paste mixer with water to cement ratio of 0.4. All the specimens were cured in ambient environment with relative humidity ( $\mathrm{RH})$ higher than $90 \%$ and temperature of $20 \pm 2{ }^{\circ} \mathrm{C}$ till the stipulated age of $3,7,28$, and 90 days. The compressive strength of pastes was tested by WAY-2000, a battery solution type compressive testing machine.

Table 1. Chemical composition of raw materials, mass $\%$

\begin{tabular}{|c|c|c|c|c|c|c|c|c|c|}
\hline Samples & $\mathrm{SiO}_{2}$ & $\mathrm{Al}_{2} \mathrm{O}_{3}$ & $\mathrm{CaO}$ & $\mathrm{Fe}_{2} \mathrm{O}_{3}$ & $\mathrm{MgO}$ & $\mathrm{SO}_{3}$ & $\mathrm{~K}_{2} \mathrm{O}$ & $\mathrm{Na}_{2} \mathrm{O}$ & $\mathrm{P}_{2} \mathrm{O}_{5}$ \\
\hline OPC & 19.59 & 5.64 & 62.63 & 3.61 & 1.52 & 3.50 & 0.82 & 0.12 & 0.12 \\
\hline GGBS & 32.54 & 14.14 & 41.07 & 0.45 & 6.03 & 3.45 & 0.68 & 0.36 & 0.05 \\
\hline PSC & 26.07 & 9.89 & 51.85 & 2.03 & 3.78 & 3.48 & 0.75 & 0.24 & 0.09 \\
\hline SSC & 31.02 & 13.23 & 42.26 & 0.58 & 5.60 & 7.10 & 0.67 & 0.33 & 0.16 \\
\hline Phosphogypsum & 26.16 & 11.25 & 41.40 & 1.25 & 5.12 & 12.39 & 0.60 & 0.24 & 0.35 \\
\hline
\end{tabular}


Table 3. Mixing proportion of the pastes $(\mathrm{W} / \mathrm{B}=0.4)$

\begin{tabular}{|c|c|c|c|c|c|c|}
\hline Samples & Cement, $\mathrm{g}$ & GGBS, $\mathrm{g}$ & Clinker, $\mathrm{g}$ & Phosphogypsum, $\mathrm{g}$ & Sodium silicate & Sodium hydroxide \\
\hline OPC & 700 & 0 & 0 & 0 & & \\
\hline PSC & 350 & 350 & 0 & 0 & & \\
\hline AAS-1 & 0 & 700 & 0 & 0 & $\sqrt{ }$ & \\
\hline AAS-2 & 0 & 700 & 0 & 0 & & \\
\hline SSC & 0 & 560 & 35 & 105 & & \\
\hline
\end{tabular}

Specific test procedure follows GB/T 17671-2005: Method of Testing Cement-Determination of Strength. And then, the specimens were broken and the small samples in the central part of the specimens were selected to soak in anhydrous ethanol to terminate the hydration for microstructural tests of SEM. The rest of sample pieces were ground in the agate mortar and dried in $60^{\circ} \mathrm{C}$ for $2 \mathrm{~h}$ to eliminate the carbonization for XRD test.

The XRF experiments were measured on Axios advanced $\mathrm{X}$-ray fluorescence instrument, in voltage range from 30 to $60 \mathrm{kV}$, with approximately $5 \mathrm{~g}$ of sample. XRD experiments were measured by X-ray Diffraction Analyzer with D/MAX-RB models of target X-ray diffraction, using copper target and continuous scan, produced by RIGAKU, a Japanese company. Morphology of the products was investigated using a scanning electron microscopy (JSM5610LV, Japan).

\section{RESULTS}

\subsection{Hydration heat evolution}

Calorimetric curves of the heat evolution and the cumulative heat evolved in $96 \mathrm{~h}$ for different cementitious systems at $20{ }^{\circ} \mathrm{C}$ are shown in Fig. 1. Similar to the typical calorimetric curve for OPC, calorimetric curves for all pastes mentioned in this paper also exhibit five distinctive periods as shown in Fig. 1 b: (i) dissolution (pre-induction) period; (ii) induction period, (iii) acceleration period; (iv) deceleration period; (v) steady period. In contrast with other cementitious systems containing GGBS, the induction period for AAS samples was relatively short that no noticeable induction period was observed for AAS-2, which may ascribe to the course that the dissolution of calcium-rich phase by $\mathrm{NaOH}$ to leach out $\mathrm{Ca}^{2+}$ and $\mathrm{Al}^{3+}$ occurs prior to the dissolution of silicate-rich phase to

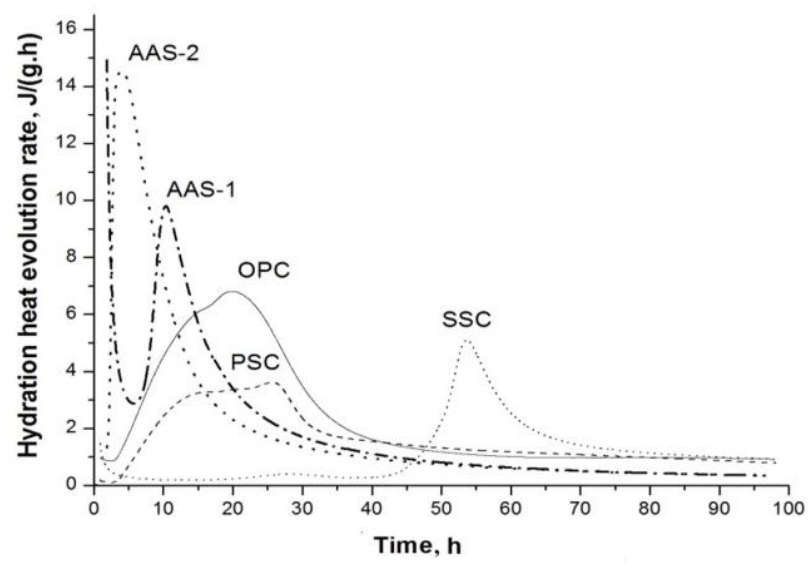

a

Fig. 1. a-Hydration curve; $b-$ heat evolved of pastes at $20{ }^{\circ} \mathrm{C}$ leach out $\left[\mathrm{SiO}_{4}\right]^{4-}$, but both of the dissolution process happens within a very short period of time, a few minutes or less. The acceleration period, during which massive products such as $\mathrm{C}-\mathrm{S}-\mathrm{H}$ and $\mathrm{C}-\mathrm{A}-\mathrm{H}$ are formed, begins instantaneously once $\left[\mathrm{SiO}_{4}\right]^{4-}$ in the solution reach a critical value, this process is fairly fast and there seem to be few hydrated products deposit on the surface of slag particles in the early hydration to block its further hydration. Accordingly, the induction period as well as the dissolution period is not evident. In addition, contrary to other cementitious systems, AAS- 1 shows obvious exothermic peaks which is termed first peak during pre-induction period, followed by an obvious induction period. This peak can be regarded as the combination of two exothermic peaks. One corresponds to the dissolution of slag grains; the other is due to the reaction of $\left[\mathrm{SiO}_{4}\right]^{4-}$ dissociated from $\mathrm{Na}_{2} \mathrm{SiO}_{3}$ and $\mathrm{Ca}^{2+}$ dissolved from the surface of slag grains to form "primary C-S-H" [19]. It is apparent that a considerable time is needed for sodium silicate activators to promote the dissolution of slag in comparison with other cementitious systems. Furthermore, it is the precipitation of "primary C-S-H" that results in the occurrence of induction period of AAS-1 [24]. Although the induction periods of OPC, PSC, and SSC differ in duration time that induction period of SSC lasts the longest while that of OPC sustains the shortest. The reason for the showing up of the induction stages are basically the same, which primarily results from the hydration of gypsum (or phosphogypsum) and $\mathrm{C}_{3} \mathrm{~A}$ to $\mathrm{AFt}$ and "primary $\mathrm{CSH}^{\mathrm{N}}$ " at initial stage, leading to $\mathrm{C}_{3} \mathrm{~A}$ being substantially consumed and slag grains as well as clinker grains being coated by newly formed $\mathrm{AFt}$ or $\mathrm{CSH}$, thus the hydration process is temporarily suppressed and comes into the so-called induction period.

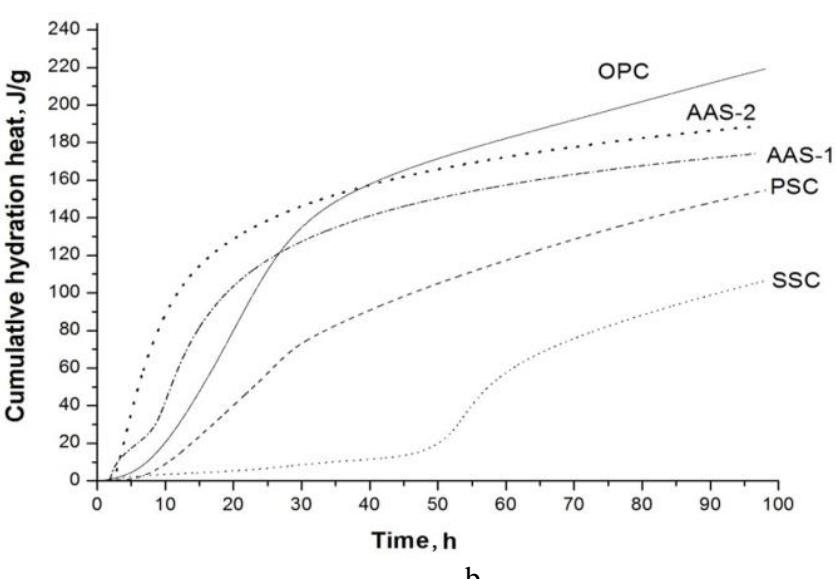


The second exothermic peaks, which is mainly caused by the hydration of slag as well as cement clinkers to form secondary $\mathrm{CSH}$ and other hydrates, appears in chronological order of AAS-2, AAS-1, OPC, PSC and $\mathrm{SSC}$, which reflect the hydration rate of testing samples as well. This is likely due to the difference in alkalinity in reaction solution determined by clinkers content or alkaline activators in view of the fact that the dosages of clinkers from low to high are SSC, PSC, and OPC and sodium hydroxide as well as sodium silicate, whose $\mathrm{pH}$ value is a bit lower than the former, are alkali activator with higher $\mathrm{pH}$ value than OPC, PSC, and SSC. Furthermore, both PSC and OPC have the third exothermic peak followed closely to the second exothermic peak. The third exothermic peak is a bit higher than the second exothermic peak and caused by the possible transformation of AFt to AFm after complete depletion of gypsum.

Fig. $1 \mathrm{~b}$ shows the cumulative hydration heat in the first $96 \mathrm{~h}$ of testing samples. It can be observed that the cumulative heat release of AAS is much higher than that of OPC, PSC, and SSC during the early $24 \mathrm{~h}$. Thereafter, the cumulative hydration heat curves of AAS are surpassed by OPC owing to the continuous ongoing hydration of OPC but the limited hydration rate of AAS. Compare with AAS- 1 and AAS-2 with the same concentration of $\mathrm{Na}_{2} \mathrm{O}$, the hydration heat release curves of AAS-2 indicate more heat evolved, and therefore a higher degree of hydration during all testing time. As regard to the development trend of cumulative heat release, the total heat release from the high to the low is OPC, AAS-2, AAS-1, PSC, and SSC, which is in accordance with previous study that AAS may has lower heat evolution rate and total heat evolution than OPC in some cases with proper mixture ratio and activator modulus in spite of the acceleration of slag hydration at initial stage by alkaline activator. The results also indicate that the hydration heat release of slag is much lower than that of clinkers for the reasons that not only the cumulative heat release of SSC, PSC, and OPC increase with the clinker increment and slag reduction, but also the cumulative heat release of clinker free AAS with $100 \%$ slag replacement and complete activation by alkalis is still lower than that of $100 \%$ OPC.

\subsection{Compressive strength}

The compressive strength development of OPC, PSC, SSC, AAS-1 and AAS-2 paste at each curing age is depicted in Fig. 2. Among the five pastes, AAS-1 paste exhibits the highest compressive strength followed by OPC, PSC, SSC in order at all testing ages and AAS-2 give the lowest compressive strength except for the early age at 3 days, which is higher than SSC but still lower than PSC. The results verify the previous studies that $\mathrm{Na}_{2} \mathrm{SiO}_{3}$ is the most effective activator in terms of strength [25-27]. In contrast with specimens of OPC, PSC, SSC, and AAS-2 which show progressive strength development, AAS-1 paste reaches to nearly $70 \mathrm{MPa}$ at 1 day, while weakens slightly thereafter and develops additional strength to more than $95 \mathrm{MPa}$ within 90 days.

It is evident that the compressive strength of AAS-1 is the highest and much higher than that of AAS-2 in spite that the hydration degree of AAS-2 is higher than AAS-1.
This can be attributable to the dual excitation effect of sodium silicate. On one hand, sodium silicate can not only promote the decomposition of $\mathrm{Ca}^{2+}$ and $\mathrm{Al}^{3+}$ from calcium rich phase but also facilitate the decomposition of $\left[\mathrm{SiO}_{4}\right]^{4-}$ and $\left[\mathrm{AlO}_{4}\right]^{5-}$ from silicate rich phase by providing $\mathrm{OH}^{-}$in hydrolytic process, of which the exciting mechanism is extremely similar with that of sodium hydroxide as well as other cementitious systems. On the other hand, sodium silicate can also supply $\left[\mathrm{SiO}_{4}\right]^{4-}$ promptly, which can compensate for the insufficiency of $\left[\mathrm{SiO}_{4}\right]^{4-}$ in the solution and accelerate the polycondensation of $\left[\mathrm{SiO}_{4}\right]^{4-}$ with $\mathrm{Ca}^{2+}$ and $\mathrm{Al}^{3+}$ to precipitate minerals with cementitious behavior. The latter excitation effect undoubtedly enhance the strength development as a result of the more hydration products formation thus leading to more compact microstructure of pastes compare with other cementitious systems.

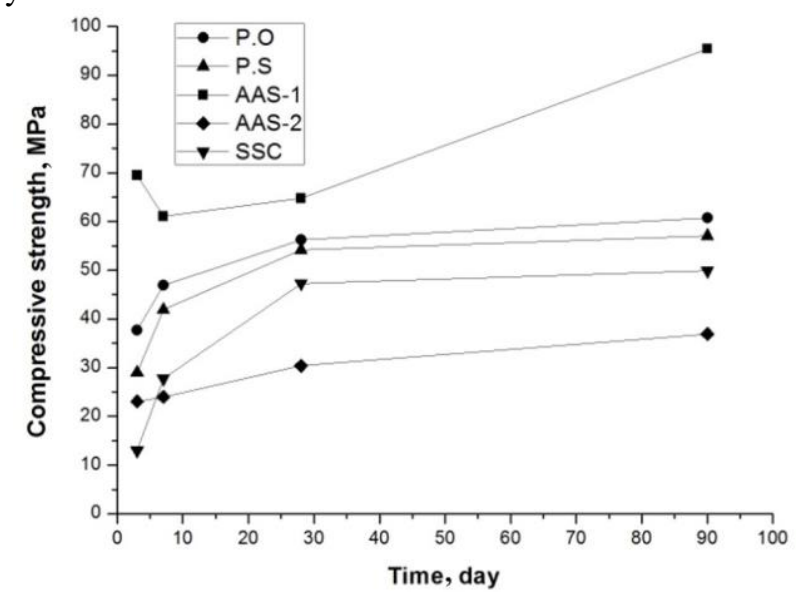

Fig. 2. Compressive strength development of the pastes

The hydration heat evolution curve of AAS-2 scarcely displays noticeable induction period as well as dissolution period. It seems that the adding of $\mathrm{NaOH}$ activator results in immediate dissolution of slag and subsequent product formation. The reaction in early hydration is so rapidly that a great deal of slag grains are unreacted or partially reacted with product shell on the surface of them and acting as a physical barrier, limiting their degree of dissolution and further hydration by keeping the ions in solution from the inner structure of slag [28]. As a result, AAS-2 exhibits the lowest compressive strength. The rapid reaction, however, may also contributed to the hydration product formation at initial age, which is a likely explanation for the higher compressive of AAS-2 pastes than SSC at early age.

In addition, the compressive strength of PSC is higher than that of SSC but lower than that of OPC at all testing age, which is consistent with the cumulative heat evolution results. This may be due to the gradually increasing clinker content in SSC, PSC, and OPC. At early stages of hydration, clinkers are needed to guarantee the alkalinity to generate lots of ettringite, which is the main contributor to early strength. While at late stages, clinker also plays an important role in late strength by generating C-S-H gel and $\mathrm{Ca}(\mathrm{OH})_{2}$, of which the former is the main contributor to late strength and the latter is the indispensable factor for slag or phosphogypsum activation. However, the strength gain of SSC and PSC is larger than that of OPC, indicating that the strength gain at late age is close related with the 
potential reactivity of slag or activation of phosphogypsum.

\subsection{XRD analysis}

XRD results of all testing pastes are presented in Fig. 3. The hydration products of PSC are similar to those of OPC at the age of 28 days except for the differences in their intensity of diffraction peaks. Compared with OPC, the characteristic peak intensity of $\mathrm{Ca}(\mathrm{OH})_{2}$ in PSC system decreases dramatically which is primarily caused by participation of pozzolanic reaction with slag elements. In addition, characteristic peaks for calcite and ettringite are also detected in OPC and PSC. While the peak intensity for ettringite is low in both OPC and PSC. At the age of 90 days, the main products are almost the same with that at age of 28 days except that the characteristic peak intensity of $\mathrm{Ca}(\mathrm{OH})_{2}$ is enhanced in OPC while weakened in PSC owing to that $\mathrm{Ca}(\mathrm{OH})_{2}$ will be kept generating in OPC system while the formation rate of $\mathrm{Ca}(\mathrm{OH})_{2}$ by clinkers is much slower than its consumption rate by slag in PSC system in the late period. Furthermore, the characteristic peaks of ettringite are almost disappeared over curing age, which is caused by the converting of ettringite to AFm.

$\mathrm{Ca}(\mathrm{OH})_{2}$ can be hardly detected with respect to SSC and AAS pastes. The characteristic peaks of gypsum and ettringite can be identified in SSC at all testing age in Fig. 3. As for AAS-1 and AAS-2 at age of 28 days, one obvious diffraction peak of calcite and tobermorite, can be observed in AAS-1 and AAS-2, respectively. However, at the age of 90 days, the strongest characteristic peak of calcite in AAS-1 system is transformed to the characteristic peak of $0.9 \mathrm{~nm}$ tobermorite, a so-called crystalline C-S-H. This may be caused by the alkaliactivated carbonatite reaction during which the calcite is activated by alkalis to form low-crystaline C-S-H [29]. Additionally, new characteristic peaks of cowlesite and calcite are detected in AAS-2 at age of 90 days. The appearance of calcite in all testing pastes may be attributed to either intermediate product of hydration [30] or the carbonization of $\mathrm{Ca}(\mathrm{OH})_{2}$ released by clinkers. This need further research.

\subsection{SEM analysis}

SEM images of different pastes aforementioned at 28 days are given in Fig. 4. The C-S-H gel can be observed in all sample pastes. Fibrous C-S-H and orthohexagonal $\mathrm{Ca}(\mathrm{OH})_{2}$ are randomly embedded in pastes of OPC and PSC, which confirm the results of XRD. In addition, the microstructure of PSC seems much denser than that of OPC, which is mainly due to the pozzolanic effect of slag that consumes a great deal of $\mathrm{Ca}(\mathrm{OH})_{2}$ with coarse crystal structure and improves the interface orientation. At the same time, C-S-H gel with more compacted structure is generated, filling in the pores of previously generated hydration products to make the structure denser possibly. However, the unreacted slag is also noticeable in the image, which may explain the lower compressive strength of PSC in spite of the denser microstructure of PSC than OPC.

In cases of AAS-1 and AAS-2 pastes, the microstructure is much denser than those of OPC and PSC pastes, and AAS-2 seem to presents a more porous formation in contrary to AAS-1. As shown in Fig. 4, hexagonal lamellar $\mathrm{Ca}(\mathrm{OH})_{2}$ crystals as well as cubic calcite crystals that oriented grow on $\mathrm{C}-\mathrm{S}-\mathrm{H}$ gel plane can also be observed on the fracture surface of the both AAS-1 and AAS-2 samples besides the C-S-H, indicating that $\mathrm{Ca}(\mathrm{OH})_{2}$ and calcite are likely to be the hydration products of AAS. The C-S-H gel in AAS-1 and AAS-2 connects to be a cohesive whole, forming a mesh structure, which is different to the radiated, agglomerated and fibrous gel generated in OPC and PSC. Though considerable amounts of $\mathrm{Ca}(\mathrm{OH})_{2}$ crystal can be seen through SEM in AAS, but no $\mathrm{Ca}(\mathrm{OH})_{2}$ crystal apart from calcite can be detected in AAS paste by XRD analysis. This may attribute to carbonization of $\mathrm{Ca}(\mathrm{OH})_{2}$ in the process of grinding prior to XRD testing.
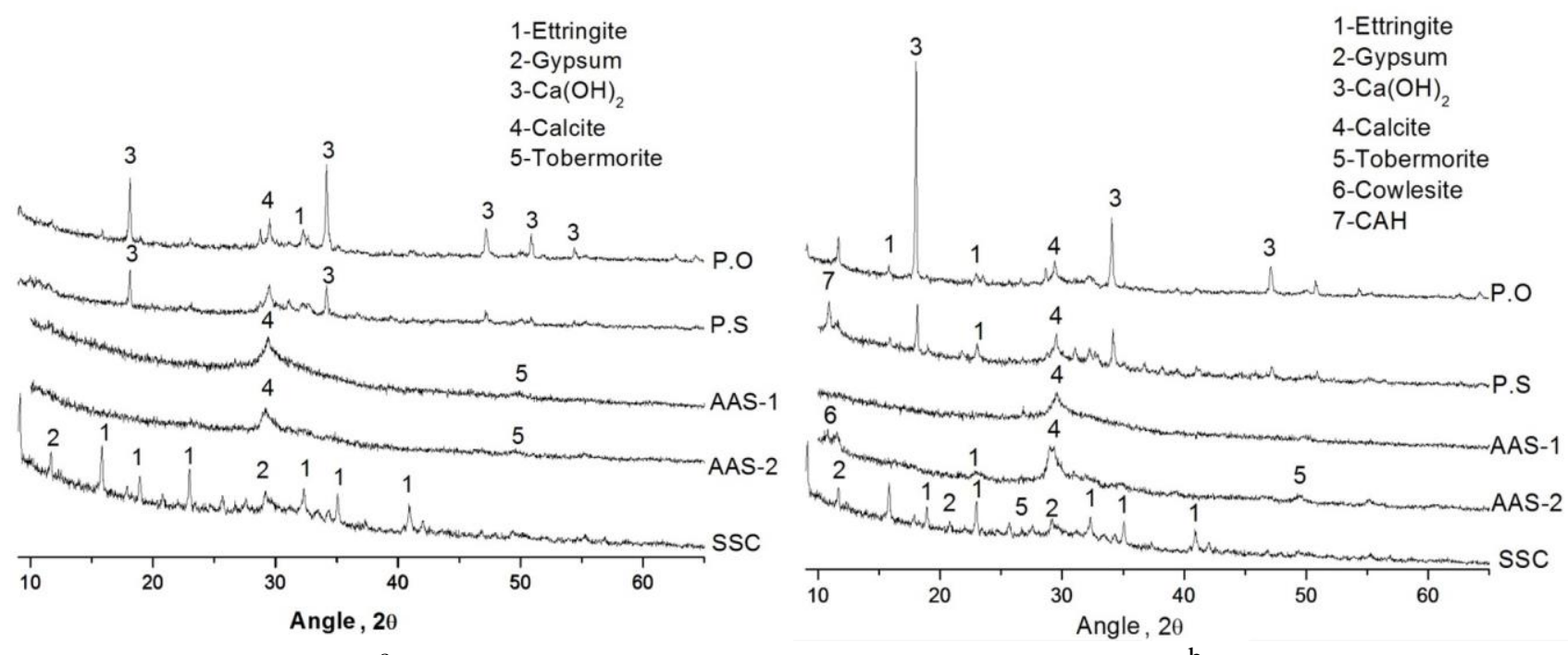

Fig. 3. XRD analysis of the pastes containing GGBS at: $a-28$ days; $b-90$ days 


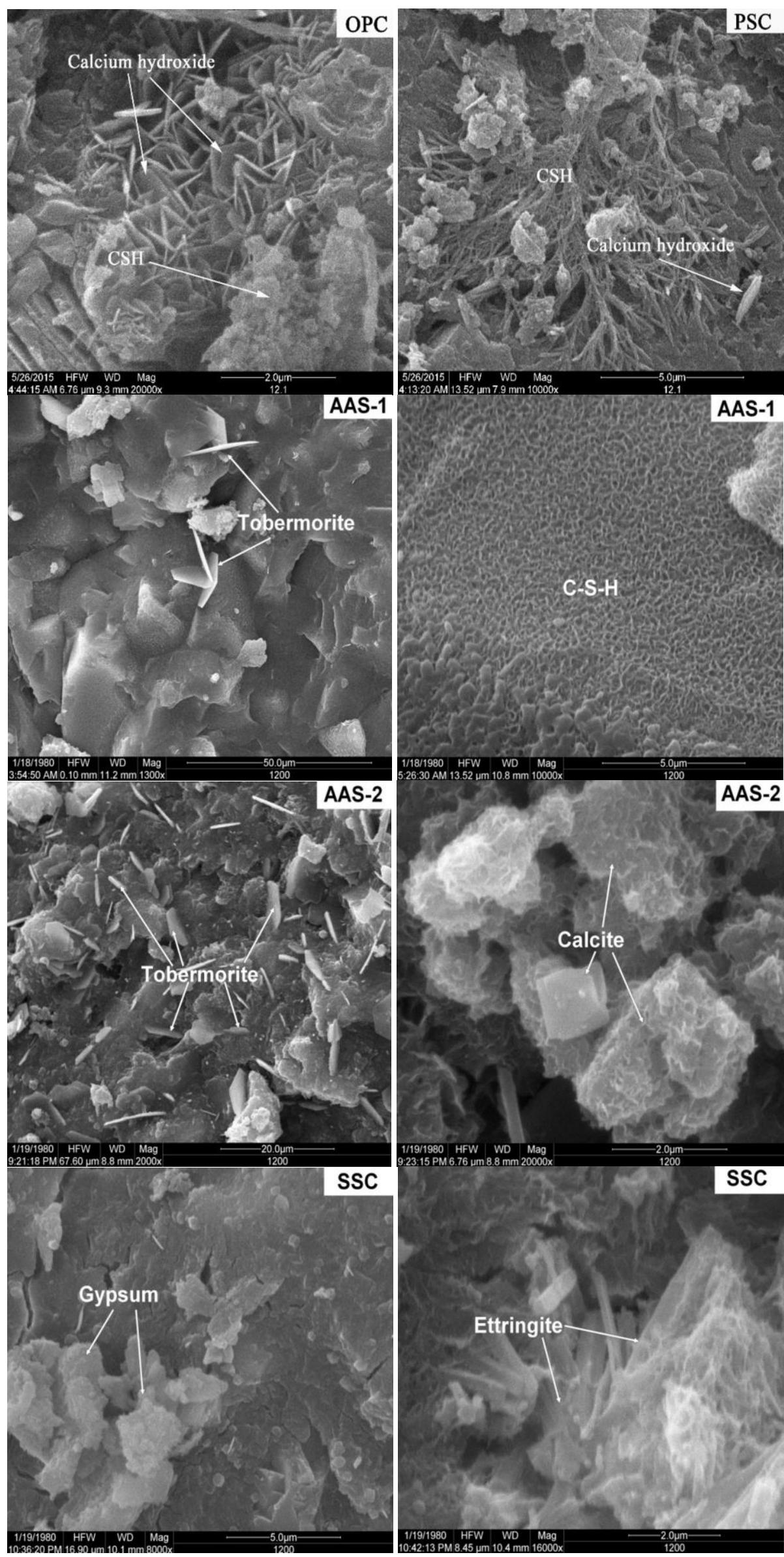

Fig. 4. SEM images of the pastes containing GGBS at 28 days 
As for SSC case, there are many needle-shape and rodlike ettringite crystals which associate and connect to form a continuous mesh structure, constituting the skeleton of the hardened pastes with fibrous C-S-H gel fills up cracks and pores in the skeleton, gradually remedying structure defects of cement paste to improve the pore structure distribution and the mechanical properties of specimens.In addition, some unhydrated phosphogypsum can also be found in SSC paste.

\section{DISCUSSION}

When the contents of $\mathrm{Na}_{2} \mathrm{O}$ in sodium silicate and sodium hydroxide solution are the same, compared with sodium silicate, the $\mathrm{pH}$ value of sodium hydroxide solution is relatively higher. The glassy structure of slag can be quickly destructed and decomposed by $\mathrm{OH}^{-}$provided by sodium hydroxide solution, releasing active silica, active lime, $\mathrm{Mg}^{2+}$ and $\mathrm{Al}^{3+}$, etc. These ions and active materials enrich continually and then further react to form CSH. The reaction process is so quick that there is no enough time for the hardened paste to develop a compact structure at early hydration time. The hydration reaction can be described by following formulas $[31,32]$ :

$$
\begin{aligned}
& \equiv \mathrm{Si}-\mathrm{O}-\mathrm{Ca}-\mathrm{O}-\mathrm{Si} \equiv+2 \mathrm{OH}^{-} \longrightarrow 2\left(\equiv \mathrm{Si}-\mathrm{O}^{-}\right)+\mathrm{Ca}(\mathrm{OH})_{2} \\
& \equiv \mathrm{Si}-\mathrm{O}-\mathrm{Si} \equiv+\mathrm{OH}^{-} \longrightarrow \mathrm{Si}-\mathrm{O}-+\mathrm{HO}-\mathrm{Si} \equiv
\end{aligned}
$$

A lot of hydrotalcite can be detected in sodium hydroxide activated slag paste. Typical hydrotalcite is layered double hydroxide (LDHs) (Fig. 5). This may attribute to the high content of $\mathrm{OH}^{-}$in sodium hydroxide solution, and high $\mathrm{Mg}^{2+}$ and $\mathrm{Al}^{3+}$ released by slag through decomposition by $\mathrm{OH}^{-}$. Anions in layers and anions between layers are connected by hydrogen bond, and anions between layers can be replaced by other anions which makes the hydration product has a complicated structure.

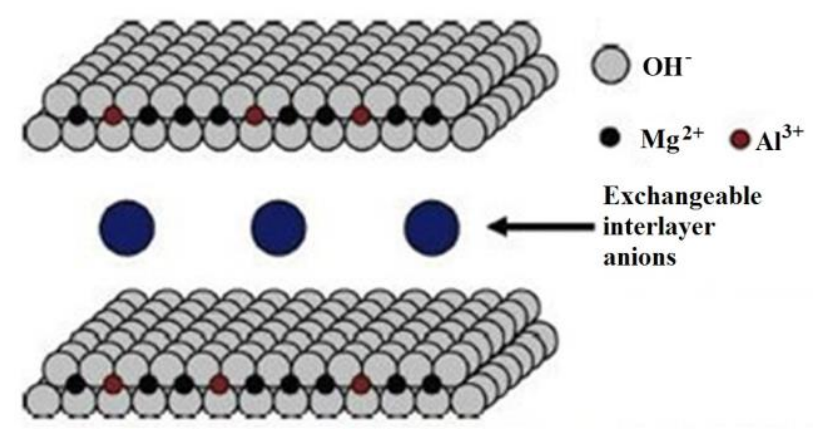

Fig. 5. Structure of $\mathrm{Mg}^{2+} / \mathrm{Al}^{3+} \mathrm{LDH}$

Through SEM and XRD analysis, tobermorite can be detected in sodium silicate activated slag. Tobermorite is a kind of $\mathrm{CSH}$ with low $\mathrm{Ca} / \mathrm{Si}$ ratio. According to other studies, $\mathrm{CSH}$ with low $\mathrm{Ca} / \mathrm{Si}$ ratio has a higher strength [33]. The $\mathrm{SiO}_{2}$ content in slag is higher than that in cement (see Table 1), moreover, sodium silicate can provide $\mathrm{Si}$, making the $\mathrm{Ca} / \mathrm{Si}$ ratio even lower. This maybe can partly explain the high compressive strength of sodium silicate activated slag paste.

The hydration process of SSC can be divided into two steps. First, the hydration of clinker which releases $\mathrm{OH}^{-}$ and generates $\mathrm{Ca}(\mathrm{OH})_{2}$, and then the generated $\mathrm{Ca}(\mathrm{OH})_{2}$ reacts with gypsum to form needle-like ettringite. The early strength of SSC is rather low, and the early formed ettringite can improve the strength of hardened SSC pastes.

\section{CONCLUSIONS}

1. The second exothermic peak of both AAS-1 and AAS2 is advanced followed by OPC, PSC and SSC in order, and no noticeable induction period is observed in AAS-2. Although AAS possesses a faster reaction rate in the initial hours, the cumulative hydration heat of AAS is lower than that of OPC, but higher than that of PSC and SSC. The induction period for SSC is relatively long and its cumulative heat of reaction is the lowest among pastes discussed in this paper.

2. AAS-1 pastes exhibit the highest compressive strength followed by OPC, PSC, SSC in order at all testing ages and AAS-2 shows the lowest compressive strength except for the early strength at 3 days, which is higher than SSC but still lower than PSC. The strength of PSC and SSC pastes develops rapidly within 28 days, and compressive strength values at 90 days is slightly lower than that of OPC.

3. C-S-H gel is the main hydration products in all cementitious materials containing GGBS in addition to some low-crystalline C-S-H, i.e., tobermorite, has also been found in AAS. There is little of $\mathrm{Ca}(\mathrm{OH})_{2}$ observed in SSC. Besides, the common hydration products aforementioned, tobermorite and calcite are found in AAS-1. Aluminum tobermorite, cowlesite and calcite are hydration products of AAS-2 as well. Furthermore, in addition to C-S-H gel, ettringite is the main hydration products of SSC as well as gypsum crystal.

\section{Acknowledgments}

This project is funded by the National Basic Research Program of China (973 Program, 2013CB035901).

\section{REFERENCES}

1. Liu, S., Wang, L., Gao, Y. Influence of Fineness on Hydration Kinetics of Supersulfated Cement Thermochimica Acta 605 2015: pp. 37-42.

2. Huntzinger, D.N., Eatmon, T.D. A Life-cycle Assessment of Portland Cement Manufacturing: Comparing the Traditional Process with Alternative Technologies Journal of Clean Products 17 2009: pp. 668-675.

3. Wang, Q., Yan, P., Feng, J. A Discussion on Improving Hydration Activity of Steel Slag by Altering Its Mineral Compositions Journal of Hazard Materials 196 2011: pp. $1070-1075$.

4. Iacobescu, R.I., Koumpouri, D., Pontikes, Y., Saban, R., Angelopoulos, G.N. Valorisation of Electric Arc Furnace Steel Slag as Raw Material for Low Energy Belite Cements Journal of Hazard Materials 196 2011: pp. 287-294.

5. Öner, M., Erdoğdu, K., Günlü, A. Effect of Components Fineness on Strength of Blast Furnace Slag Cement Cement and Concrete Research 33 2003: pp. 463-469.

6. Escalante, J.I., Espinoza, L.J., Gorokhovsky, A. Coarse Blast Furnace Slag as A Cementitious Material, Comparative Study as A Partial Replacement of Portland Cement and as 
an Alkali Activated Cement Construction and Building Materials 23 2009: pp. 2511-2517.

7. Bellmann, F., Stark, J. Activation of Blast Furnace Slag by A New Method Cement and Concrete Research 39 2009: pp. $644-650$.

https://doi.org/10.1016/j.cemconres.2009.05.012

8. Toutanji, H., Delatte, N., Aggoun, S. Effect of Supplementary Cementitious Materials on the Compressive Strength and Durability of Short-Term Cured Concrete Cement and Concrete Research 34 2004: pp. 311-319. https://doi.org/10.1016/j.cemconres.2003.08.017

9. Bellmann, F., Stark, J. Activation of Blast Furnace Slag by A New Method Cement and Concrete Research 39 2009: pp. $644-650$.

https://doi.org/10.1016/j.cemconres.2009.05.012

10. Puertas, F., Amat, T., Fernández-Jiménez, A. Mechanical and Durable Behaviour of Alkaline Cement Mortars Reinforced with Polypropylene Fibres Cement and Concrete Research 33 2003: pp. 2031-2036.

11. Song, S., Sohn, D., Jennings, H.M. Hydration of AlkaliActivated Ground Granulated Blast Furnace Slag Journal of Materials Science 35 2000: pp. 249-257. https://doi.org/10.1023/A:1004742027117

12. Pratt, P.L., Wang, S., Pu, X. Alkali-activated Slag Cement and Concrete: A Review of Properties and Problems Advances in Cement Research 7 1995: pp. 93-102.

13. Krizan, D., Zivanovic, B. Effects of Dosage and Modulus of Water Glass on Early Hydration of Alkali-Slag Cements Cement and Concrete Research 32 2002: pp. 1181-1188. https://doi.org/10.1016/S0008-8846(01)00717-7

14. Shi, C., Qian, J. High Performance Cementing Materials from Industrial Slags - A Review Resources Conservation and Recycling 29 2000: pp. 195-207. https://doi.org/10.1016/S0921-3449(99)00060-9

15. Haha, M.B., Lothenbach, B., Saout, G.L. Influence of Slag Chemistry on the Hydration of Alkali-Activated Blastfurnace Slag - Part II: Effect of $\mathrm{Al}_{2} \mathrm{O}_{3}$ Cement and Concrete Research 41 2011: pp. 955-963. https://doi.org/10.1016/j.cemconres.2011.05.002

16. Gruskovnjak, A., Lothenbach, B., Winnefeld, F. Hydration Mechanisms of Super Sulphated Slag Cement Cement and Concrete Research 38 2008: pp. 983-992. https://doi.org/10.1016/j.cemconres.2008.03.004

17. Liu, S., Wang, L., Gao, Y. Comparing Study on Hydration Properties of Various Cementitious Systems Journal of Thermal Analysis and Calorimetry 118 2014: pp. $1483-1492$. https://doi.org/10.1007/s10973-014-4052-4

18. Bellmann, F., Stark, J., Matschei, T. Hydration Behaviour of Sulphate-activated Slag Cements Chinese Nursing Research 17 2005: pp. 167-178.

19. Smolczyk, H.G., Die Hydratations Produkte Hüttensandreicher Zemente Zem.-Kalk-Gips 5 1965: pp. $238-246$.

20. Stark, J. Sulfathüttenzement, Wiss. Z. Hochsch. Archit. Bauwes. Weimar 41 1995: pp. 7-15.

21. Gruskovnjak, A., Lothenbach, B., Winnefeld, F. Quantification of Hydration Phases in Supersulfated
Cements: Review and New Approaches Cement Research 23 2011: pp. 265-275.

Advances in https://doi.org/10.1680/adcr.2011.23.6.265

22. Tucci, G. Strength Development of Concrete Incorporating High Levels of Ground Granulated Blast-Furnace Slag at Low Temperatures ACI Structural Journal 97 2000: pp. $66-70$.

23. Brough, A.R., Atkinson, A. Sodium Silicate-based, AlkaliActivated Slag Mortars: Part I. Strength, Hydration and Microstructure Cement and Concrete Research 32 2002: pp. $865-879$. https://doi.org/10.1016/S0008-8846(02)00717-2

24. Shi, C., Day, R.L. A Calorimetric Study of Early Hydration of Alkali-Slag Cements Cement and Concrete Research 25 1995: pp. $1333-1346$. https://doi.org/10.1016/0008-8846(95)00126-W

25. Bougara, A., Lynsdale, C., Ezziane, K. Activation of Algerian Slag in Mortars Construction and Building Materials 23 2009: pp. 542-547. https://doi.org/10.1016/j.conbuildmat.2007.10.012

26. Haha, M.B., Saout, G.L., Winnefeld, F., Lothenbach, B. Influence of Activator Type on Hydration Kinetics, Hydrate Assemblage and Microstructural Development of AlkaliActivated Blast-furnace Slags Cement and Concrete Research 41 2011: pp. 301-310. https://doi.org/10.1016/j.cemconres.2010.11.016

27. Escalante, J.I., Fuentes, A.F., Gorokhovsky, A., Fraire, P.E., Mendoza, G. Hydration Products and Reactivity of Blast-Furnace Slag Activated by Various Alkalis Journal of American Ceramic Society 86 2003: pp. $2148-2153$.

28. Berhan, S., Robert, T., Sulapha, P. Very Early-aged Reaction Kinetics and Microstructure Development in Alkali-Activated Slag Cement and Concrete Composites 55 2015: pp. $91-102$. https://doi.org/10.1016/j.cemconcomp.2014.09.001

29. Yin, S., Wen, Z., Yu, Q. Study on Reaction Products of Alkali-Activated Carbonatites Cementitious Material Journal of the Chinese Ceramic Society 32 2004: pp. 311-316.

30. Aydın, S., Baradan, B. Effect of Activator Type and Content on Properties of Alkali-Activated Slag Mortars Composites Part B Engineering 57 2014: pp. 166-172. https://doi.org/10.1016/j.compositesb.2013.10.001

31. Xu, B. Preparation and Investigation of Hydration Mechanism and Properties of Solid Alkaline Slag Cement: Doctoral Dissertation. Beijing: Tsinghua University, 1995.

32. Talling, B., Brandstetter, J. Present State and Future of Alkali-Activated Slag Concretes, Fly Ash, Silica Fume, Slag and National Pozzolana Concrete. Proceedings of Third International Conference, Trondheim, Norway. ACI, 1989: pp. $1519-1545$.

33. Lothenbach, B., $\quad$ Scirvener, K., $\quad$ Hooton, R.D. Supplementary Cementitious Materials Cement and Concrete Research 41 2011: pp. 1244-1256. https://doi.org/10.1016/j.cemconres.2010.12.001 